\title{
Expression Technologies for DNA and RNA
}

National Cancer Institute

\section{Source}

National Cancer Institute. Expression Technologies for DNA and RNA. NCI Thesaurus. Code C19132.

Technologies to induce the process of transcription of specific information embodied in the DNA into mRNA (messenger RNA), which is then translated into proteins. 